\title{
Joining a Monetary Union: Stabilisation Costs Versus Stabilisation Bias
}

\author{
Marcelo Sánchez \\ European Central Bank
}

\begin{abstract}
Currency union participation may create a welfare tradeoff relating to monetary factors. Stabilisation costs arise from asymmetric shocks across the union. Countries pursuing discretionary national monetary policies benefit from a committed common central bank, which eliminates Svensson's(1997) stabilisation bias. Currency union membership is favoured by greater price stability focus and commitment of the common central bank, nominal flexibility, and business cycle synchronisation. Monetary union stabilisation performance also improves with lower variability and persistence of cost-push shocks - the latter feature being detectable only for persistence. The degree of monetary policy robustness to parameter uncertainty has somewhat less clear-cut implications.
\end{abstract}

- JEL Classification: E32, E52, E58

- Keywords: Monetary Union, Asymmetric Shocks, Stabilisation Bias, Conservative Central Bank, Robust Policy.

\section{Introduction}

The modern literature on monetary policy has stressed the gains from commitment in comparison with discretion, with the latter leading to inefficient macroeconomic stabilisation. In dynamic general equilibrium models, the performance gap is characterised as a "stabilisation bias" (see e.g. Svensson, 1997; Dennis and Söderström, 2006). When commitment is not feasible, a welfare

\footnotetext{
*Corresponding address: European Central Bank. Kaiserstrasse 29. D-60311. Frankfurt am Main. Germany. Tel: +49 691344 6531; fax: +49 691344 7602. E-mail address: marcelo.sanchez@ecb.int. @2011-Center for Economic Integration, Sejong Institution, Sejong University, All Rights Reserved.
} 
improvement over discretion can be achieved by appointing a "conservative central banker", i.e. by delegating monetary policy to someone who is more inflation-averse than the social planner - an idea going back to Rogoff (1985) (see also Clarida et al., 1999). The delegation decision may also be affected by uncertainty about the persistence of shocks. Tillmann (2009) analyses the involved "robust delegation" process, showing that persistence uncertainty concerning costpush shocks raises both the stabilisation bias and the degree of optimal monetary conservatism. ${ }^{1}$

Regarding currency union, it is typical to see analyses that examine stabilisation costs arising from cross-country asymmetries, which are one part of the monetary implications of this type of multicountry arrangement. In this regard, in a monetary union the central bank is normally seen as responding exclusively to union-wide averages of inflation and output, paying attention to country-specific shocks only insofar as they affect union-wide averages. The standard analysis of stabilisation costs takes as exogenous the remaining monetary factors (regarding possible credibility effects from joining) alongside market integration and political considerations. Here we integrate the two sides of monetary aspects, combining the study of stabilisation costs and possible welfare gains over discretion - these gains being attributable to delegation to an inflation averse central bank. Both dimensions of the "monetary package" implied by currency union membership are affected by the realisations and persistence of asymmetric shocks. ${ }^{2}$ The idea here is that a currency union entails stabilisation costs but may also offer potential monetary credibility gains to member states. We focus on the comparison between discretion under monetary autonomy and commitment under a currency union. The framework of analysis can also tackle other monetary policy combinations, but these are obviously dominated by monetary autonomy. We abstract from nonmonetary pro-currency union features such as enhanced trade and financial integration. ${ }^{3}$ In order to facilitate an analytical solution, the model is a simplified

${ }^{1}$ For robust control studies of monetary policy, see Hansen and Sargent (2008) and Giannoni (2007).

${ }^{2}$ This notion is familiar in standard analyses of stabilisation costs. The asymmetry and persistence of shocks also matter here for the stabilisation bias. Under commitment, inflation expectations are better anchored as market participants know that inflation is less affected by the cost-push shock. The "sacrifice ratio" in terms of expected output reduction is smaller. The relevance of these channels is greater for more persistent cost-push disturbances, which strengthens the gains from commitment (and thus the stabilisation bias).

${ }^{3}$ Another feature that makes the theoretical case for monetary union stronger is the possibility that the latter regime induces more structural reforms, as there is a need to make the economies of participating countries more flexible after monetary sovereignty is relinquished (Calmfors, 2001). 
New Keynesian model.

Other features of our approach to integrating asymmetric costs and credibility are as follows. First, we allow for common shocks, or more precisely, for a nonzero cross-country correlation of disturbances. This enables us to have the notion of a threshold cross-country shock correlation for which the currency union's "monetary package" breaks even. Second, we allow for cost-push shocks to be serially correlated, which is known to have an influence on the magnitude of the stabilisation bias facing discretionary national policies. In light of the role of shocks' persistence in determining the gains from commitment, we also allow the monetary authority to be uncertain along this dimension, thus motivating robust policies. ${ }^{4}$ Third, we use an economically interpretable metric (namely, equivalent permanent inflation and output costs), as opposed to simply comparing welfare losses. ${ }^{5}$ These features distinguish us from van Aarle et al. (2008), who also integrate asymmetric costs and commitment using a new-Keynesian model to analyse the euro area accession process. Angelini et al. (2008) consider the problem of monetary policy in an asymmetric currency area, but our goal is different from theirs, which is to assess empirically whether the ECB may improve its performance by reacting to country variables rather than to targeted area-wide variables. Our interest in cross-country shock correlations distinguishes us from monetary union studies that look into parametric asymmetries, such as those concerning the degrees of competition and nominal rigidity. For instance, Benigno (2004) focuses on nominal rigidities, showing that the currency union's central bank should react more strongly to the inflation originating from the less flexible participating country. Lombardo (2006) finds that, if the degree of competition differs between countries, the common optimal rule could involve placing a greater weight on the more flexible countries.

In section II we derive optimal monetary policy and the size of the stabilisation bias under "conventional" (i.e. not robust) policies, as well as introducing persistence uncertainty about the cost-push shock (which gives rise to robust policies). In section III we compare the stabilisation and credibility performance of a currency union versus monetary autonomy. Section IV concludes.

\footnotetext{
${ }^{4}$ An interesting extension of the paper would be if the policymaker were uncertain about the size of crosscountry correlation. We leave this extension for future research.

${ }^{5}$ For simplicity, we abstract from open economy features (other than currency union membership) and the demand side of the economy, including the role of fiscal stabilisation.
} 


\section{Monetary Autonomy and the Currency Union}

We consider two regimes: i) when discretionary monetary policy is decided at the country level (labelled regime $n$ ), and ii) when the "single" monetary authority (SMA) adopts decisions that amount to commitment for the whole of the twocountry currency union (labelled regime $u$ ). For the currency union, this section and the Appendices will later introduce three other regimes, namely, discretion (labelled regime $u d$ ) and two other where the social planner delegates policy to a "conservative" central banker and in a robust fashion (labelled regimes $u c$ and $u r$, respectively).

\section{A. Monetary autonomy ${ }^{6}$}

Let us begin with the regime in which a given country $i(\mathrm{i}=1, \ldots, N)$ pursues discretionary monetary policy. The central bank is assumed to set the output gap to minimise the welfare loss arising from variability in inflation and output. The period loss function is

$$
\Gamma_{i t}=x_{i t}^{2}+\chi \pi_{i t}^{2}
$$

where $\chi \geq 0$ is the central bank weight on inflation aversion relative to output stabilisation.

Inflation $\left(\pi_{i t}\right)$ is described by a forward-looking Phillips curve, which can be obtained from linearising an equilibrium relation derived from a simple stickyprice general equilibrium model:

$$
\pi_{i t}=\beta E_{t} \pi_{i t+1}+\kappa x_{i t}+\varepsilon_{i t}
$$

where $E_{t}$ is the expectations operator (conditional on information up to $t$ ), $\beta \in(0,1)$ is the discount factor, $x_{i t}$ is the output gap and $\varepsilon_{i t}=\rho \varepsilon_{i t-1}+\xi_{i t}$ is a serially correlated cost-push shock, with $\rho \in(0,1) .{ }^{7}$ In $(2)$, the slope coefficientK measures inversely the degree of nominal rigidities.

As just mentioned, country-specific shocks $\varepsilon_{i t}$ are here introduced as cost-push

\footnotetext{
${ }^{6} \mathrm{~A}$ setup comparable to that in this subsection can be consulted in Walsh (2003a) and Tillmann (2009). ${ }^{7} \xi_{i t}$ is i.i.d. white noise with variance $\sigma_{\xi}^{2}$. Therefore, we have $\sigma_{\varepsilon}^{2}=\sigma_{\xi}^{2} /\left(1-\rho^{2}\right)$. In the context of robust policies, we shall below be more general concerning the upper bound for the serial correlation coefficient, namely: $\rho \in\left(0, \rho_{h}\right)$, with $\rho_{h}$ not necessarily equal to 1 .
} 
shocks. A - say - positive realisation of the latter induces higher inflation, for given values of inflation expectations about the future and the output gap. ${ }^{8}$ As said above, for simplicity this paper abstracts from the demand side of the economy, and thus in particular from demand shocks. Under monetary autonomy, unlike supply shocks that modify the tradeoff facing the central bank, demand disturbances should not have any effect on the economy as they can be offset by appropriately setting monetary policy. In contrast, in a monetary union context asymmetric shocks of either type imply that the single monetary authority's decisions lead to spillovers across countries which are hit differently by unforeseen events.

A discretionary central bank policy takes expectations as given. The first order condition of maximising (1) subject to (2) requires ${ }^{9}$

$$
x_{i t}=\kappa \chi \pi_{i t}
$$

While the persistence properties of the cost-push disturbance do not influence targeting rule (3), they do affect equilibrium inflation and output, which equal

$$
\begin{aligned}
\pi_{i t}^{n} & =\frac{1}{1-\beta \rho+\kappa^{2} \chi} \varepsilon_{i t} \\
\pi_{i t}^{n} & =-\frac{\kappa \chi}{1-\beta \rho+\kappa^{2} \chi} \varepsilon_{i t}
\end{aligned}
$$

The more persistent shocks are (the higher $\rho$ ), the less stabilised inflation and output gap movements. Equations (4) and (5) are reduced-form expressions for inflation and the output gap. As such, they combine market-related developments (as captured by the New Keynesian Phillips curve (2)) and the central bank's response that trades off inflation and output costs in line with (3).

\section{B. The Currency Union}

Turning to monetary union, we concentrate on the case when the SMA is able to reach the commitment solution. ${ }^{10}$ The latter amounts to credibly setting a non-

${ }^{8}$ Equation (2) is often derived for given markups for prices and wages. Therefore, cost-push shocks can be partly interpreted as stemming from random (and possibly persistent) changes in those markups.

${ }^{9}$ The targeting rule (3) would still hold if we allowed for an Euler equation for output, as the latter would not be binding for the policymaker's problem.

${ }^{10}$ The Appendix shows that this can be achieved when discretion is combined with delegation to a conservative central bank with inflation weight equal to $\chi^{P} /(1-\beta \rho)$, where $\chi^{P}$ captures the social planner's inflation concerns. 
inertial rule characterised by ${ }^{11}$

$$
\begin{aligned}
& \pi_{t}^{u}=b_{\pi}^{u} \varepsilon_{t} \\
& \chi_{t}^{u}=b_{x}^{u} \varepsilon_{t}
\end{aligned}
$$

where $b_{\pi}^{u}$ and $b_{x}^{u}$ are constants to be determined. Inflation is the same at the country and area-wide levels, that is, $\pi_{i t}^{u}=\pi_{t}^{u} \cdot{ }^{12}$ Given the rule in (6)-(7), and taking into account (2), equilibrium inflation equals $\pi_{t}^{u}=\left(\kappa x_{t}^{u}+\varepsilon_{t}\right) /(1-\beta \rho)$, and can ultimately be expressed as

$$
\pi_{i t}^{u}=\pi_{t}^{u}=\frac{1-\beta \rho}{(1-\beta \rho)^{2}+\kappa^{2} \chi} \varepsilon_{t}
$$

while, again using (2), output at the country level equals

$$
x_{i t}^{u}=\frac{(1-\beta \rho)^{2}}{\kappa\left[(1-\beta \rho)^{2}+\kappa^{2} \chi\right]} \varepsilon_{t}-\frac{1}{\kappa} \varepsilon_{i t}
$$

Proposition 1. Relative to a discretionary national monetary policy, commitment in a currency union entails a welfare tradeoff for participating countries.

Proof. We proceed in two steps, disentangling the welfare effects of currency union participation in terms of stabilisation costs (unfavourable) and the stabilisation bias (favourable). We show:

(i) that discretion in a currency union entails costs for any given participating country in comparison with discretion at home (except in the borderline case of perfect cross-country correlation with the other member states, when the outcome is neutral).

(ii) that, under currency union membership, commitment improves national welfare relative to discretion.

Concerning (i), applying the same logic leading to (4) and (5) under monetary autonomy, equilibrium inflation for a discretionary currency union (labelled regime $u d$ ) is given by $\pi_{t}^{u d}=\varepsilon_{t} /\left[1-\beta \rho+\kappa^{2} \chi\right]$. Using $\pi_{i t}^{u d}=\pi_{t}^{u d}$, the country-level variables

\footnotetext{
${ }^{11}$ Union-wide variables are denoted by dropping subindex $i$; for instance, $\pi_{t} \equiv \Sigma_{i=1}^{N} \pi_{i t} / N$.

${ }^{12}$ It is typical to assume that the same goods are produced in all member states. As the exchange rates among member states are fixed, inflation is the same across countries. See Sanchez(2010) for a study relaxing this assumption.
} 
under regime $u d$ can be found to equal

$$
\begin{gathered}
\pi_{i t}^{u d}=\pi_{i t}^{n}-\frac{1}{1-\beta \rho+\kappa^{2} \chi}\left(\varepsilon_{i t}-\varepsilon_{t}\right) \\
\pi_{i t}^{u d}=\pi_{i t}^{n}-\frac{1-\beta \rho}{\kappa\left[1-\beta \rho+\kappa^{2} \chi\right]}\left(\varepsilon_{i t}-\varepsilon_{t}\right)
\end{gathered}
$$

From (10) and (11), it is clear that there tends to be greater macroeconomic variability in the discretionary currency union than under monetary autonomy. The only exception is when $\operatorname{corr}_{\varepsilon_{\varepsilon} \varepsilon} \equiv E\left(\varepsilon_{i t} / \varepsilon_{t}\right) / \sigma_{\varepsilon}^{2}=1$, that is, when there is perfect crosscountry correlation with the other member states, in which case the outcome is neutral.

As regards (ii), for a participating country national welfare is higher under commitment than under discretion if $\Psi \equiv E \Gamma_{i t}^{u d}-E \Gamma_{i t}^{u}=\left[E\left(x_{i t}^{u d}\right)^{2}+\chi E\left(\pi_{i t}^{u d}\right)^{2}\right]$ $-\left[E\left(x_{i t}^{u}\right)^{2}+\chi E\left(\pi_{i t}^{u}\right)^{2}\right]>0$, which holds if and only if

$$
\Psi=\chi \sigma_{\varepsilon}^{2}\left\{\frac{1+\kappa^{2} \chi}{\left[1-\beta \rho+\kappa^{2} \chi\right]^{2}}\right\}-\chi \sigma_{\varepsilon}^{2}\left\{\frac{(1-\beta \rho)^{2}+\kappa^{2} \chi}{\left[(1-\beta \rho)^{2}+\kappa^{2} \chi\right]^{2}}\right\}>0
$$

which is true since $\Psi=(\beta \rho \kappa \chi)^{2} \sigma_{\varepsilon}^{2} / H$, where $H \equiv\left[1-\beta \rho+\kappa^{2} \chi\right]^{2}\left[(1-\beta \rho)^{2}+\kappa^{2} \chi\right]>0$. QED.

Instead of directly using (8) and (9), our simulations (in section 3) adopt a more general approach that embeds the case of monetary union's commitment as a baseline case. The more general corresponding expressions are:

$$
\begin{gathered}
\pi_{i t}^{u}=\pi_{t}^{u}=\frac{1-\varphi \beta \rho_{b}}{\left(1-\beta \rho_{b}\right)\left(1-\varphi \beta \rho_{b}\right)+\kappa^{2} \chi} \varepsilon_{t} \\
x_{i t}^{u}=\frac{\left(1-\beta \rho_{b}\right)\left(1-\varphi \beta \rho_{b}\right)}{\kappa\left[\left(1-\beta \rho_{b}\right)\left(1-\varphi \beta \rho_{b}\right)+\kappa^{2} \chi\right]} \varepsilon_{t}-\frac{1}{\kappa} \varepsilon_{i t}
\end{gathered}
$$

where $\varphi \geq 0$ and $\rho_{b}$ denotes the baseline value chosen for $\rho$ in our simulations below. ${ }^{13}$

The generalisation in (8') and (9') exploits the circumstance that, in this paper, policy weights under delegation (be it with or without parameter uncertainty) adopt

\footnotetext{
${ }^{13}$ As explained below, our simulations incorporate robustness concerns by setting the baseline value of the serial correlation coefficient such that $\rho_{b} \in\left(0, \rho_{h}\right)$, with the highest admissible value $\rho_{h}$ being allowed to be lower than 1 .
} 
the general form $\chi^{P}=1 /\left(1-\varphi \beta \rho_{b}\right)$. Over the range of plausible values for $\varphi$ (namely, $\varphi \geq 0$ ), we can characterise five possible cases concerning the monetary authority's intentions: a) full discretion, one extreme case given by $\varphi=0$; b) full commitment, without concern for robustness, which formally correspond to expressions (8) and (9), i.e. when $\varphi=1$; c) imperfect commitment, without concern for robustness, which is captured by $\varphi \in(0,1)$; d) full commitment, with concern for robustness, for $\varphi=\rho_{h} / \rho_{b}>1$; e) full commitment, with imperfect concern for robustness, for $\varphi$ $\in\left(1, \rho_{h} / \rho_{b}\right)$. Over the range of $\varphi$, this coefficient can thus be seen as measuring the "degree of commitment" of the central bank over $\varphi \in[0.1]$. Moreover, for values of $\varphi>1$ this coefficient measures the "degree of robustness" concerning uncertainty about the admissible range of $\rho$.

In order to understand cases d) and e) - which correspond to scenarios involving parameter uncertainty - we need to consider the optimal delegation problem which allows for uncertain shock persistence in a monetary union. More concretely, here we assume that there is uncertainty about the persistence of cost-push shocks. Economic agents (the SMA, the social planner and the public) only know that $\rho$ lies in a subset of the unit interval: $\rho \in\left[\rho_{l}, \rho_{h}\right]$, with $0 \leq \rho_{l}<\rho_{h}<1$. The planner is concerned about persistence uncertainty as it delegates monetary policy. The planner is assumed not to be able to figure out a probability distribution over the admissible range for $\rho$. Delegation instead proceeds along the lines of a minmax approach, whereby the social planner minimises the welfare loss arising from the worst possible outcome under persistence uncertainty (see Tillmann, 2009, for details). This robust delegation problem is given by $\min _{\chi^{\prime \prime}} \max _{\rho \in\left[\rho_{n}, \rho_{l}\right]}\left[E\left(x_{i t}^{u d}\right)^{2}+\chi^{P} E\left(\pi_{i t}^{u d}\right)^{2}\right]$. National inflation and output under a discretionary currency union can be found using the logic leading to (4) under monetary autonomy to also compute $x_{t}^{u d}$, as well as taking $\pi_{i t}^{u d}=\pi_{t}^{u d}$ into account. The problem can thus be written as

$$
\min _{\chi^{u \prime}} \max _{\rho \in\left[\rho_{t}, \rho_{h}\right]}\left[\left(\frac{\kappa \chi^{u r}}{1-\beta \rho+\kappa^{2} \chi^{u r}}\right)^{2}+\chi^{P}\left(\frac{1}{1-\beta \rho+\kappa^{2} \chi^{u r}}\right)^{2}\right]
$$

where the loss function depends on the social planner's inflation weight, $\chi^{P}$.

The maximisation sub-problem in (12) yields $\rho=\rho_{h}$, signalling that the loss function is increasing in $\rho$. The planner overestimates the true degree of shock persistence with the aim of minimising the welfare loss from shock persistence uncertainty. Conditional on this, the minimisation in (12) amounts to 


$$
\min _{\chi^{u r}}\left[\left(\frac{\kappa \chi^{u r}}{1-\beta \rho_{h}+\kappa^{2} \chi^{u r}}\right)^{2}+\chi^{P}\left(\frac{1}{1-\beta \rho_{h}+\kappa^{2} \chi^{u r}}\right)^{2}\right]
$$

The first order condition is given by $\chi^{u r}=\chi^{P} /\left(1-\beta \rho_{h}\right)$. The optimal inflation weight of the SMA increases with persistence uncertainty (larger $\rho_{h}$ ) and is higher than the social planner's corresponding weight.

\section{Simulations}

Our simulations compare the cases of discretionary monetary autonomy (regime $n$ ) and a committed SMA (regime $u$ ). Welfare losses from the former regime (labelled $\Gamma_{i t}^{n}$ ) can be obtained by plugging (4) and (5) into (1), while the corresponding losses for the latter regime (labelled $\Gamma_{i t}^{u}$ ) result from plugging ( $\left.8^{\prime}\right)$ and (9') into (1). We carry out two types of comparisons. First, in Figure 1 we report $\gamma_{i}^{*}$, the threshold value of the cross-country correlation coefficient for which $E \Gamma_{i t}^{n}=E \Gamma_{i t}^{u}$. In this case, stabilisation costs are exactly offset by the elimination of the stabilisation bias, with the "monetary package" involved in the currency union thus breaking even. Second, in Figure 2 we undertake a welfare comparison exercise. The welfare metric used follows Jensen (2002). We compute the equivalent permanent increase in inflation and output (denoted by $\tilde{\pi}$ and $\tilde{x}$, respectively) as a measure of the cost implied by relinquishing monetary sovereignty, that is, $\tilde{\pi}=100 \times \sqrt{(1-\beta)\left(E_{t} \Gamma_{i t}^{u}-E_{t} \Gamma_{i t}^{n}\right) / \chi}$ and $\tilde{\pi}=100 \times \sqrt{(1-\beta)\left(E_{t} \Gamma_{i t}^{n}-E_{t} \Gamma_{i t}^{u}\right)}$. We believe that combining these two types of comparisons can prove useful. In many instances, the two comparisons may concord, as a given parameter change elicits - say - a lower threshold crosscountry correlation as well as permanent decreases in inflation and output. This notwithstanding, the threshold cross-country correlation is a highly non-linear function of many parameters, so that the computation of the former might lead to various possible simulation results depending on the specific calibration chosen. As we shall see below in one case (concerning a higher degree of robustness of the SMA), the permanent reduction in inflation and output associated with this sensitivity analysis is not matched by a fall in the threshold cross-country correlation, but rather with an increase in the latter.

For calibration purposes, we use the following baseline values and ranges for the parameters. As in Jensen(2002), we have in mind an annual (as opposed to a quarterly) calibration. The discount factor, $\beta$, is set throughout to 0.96 (equivalent 
Figure 1. Threshold value of the cross-country correlation coefficient.
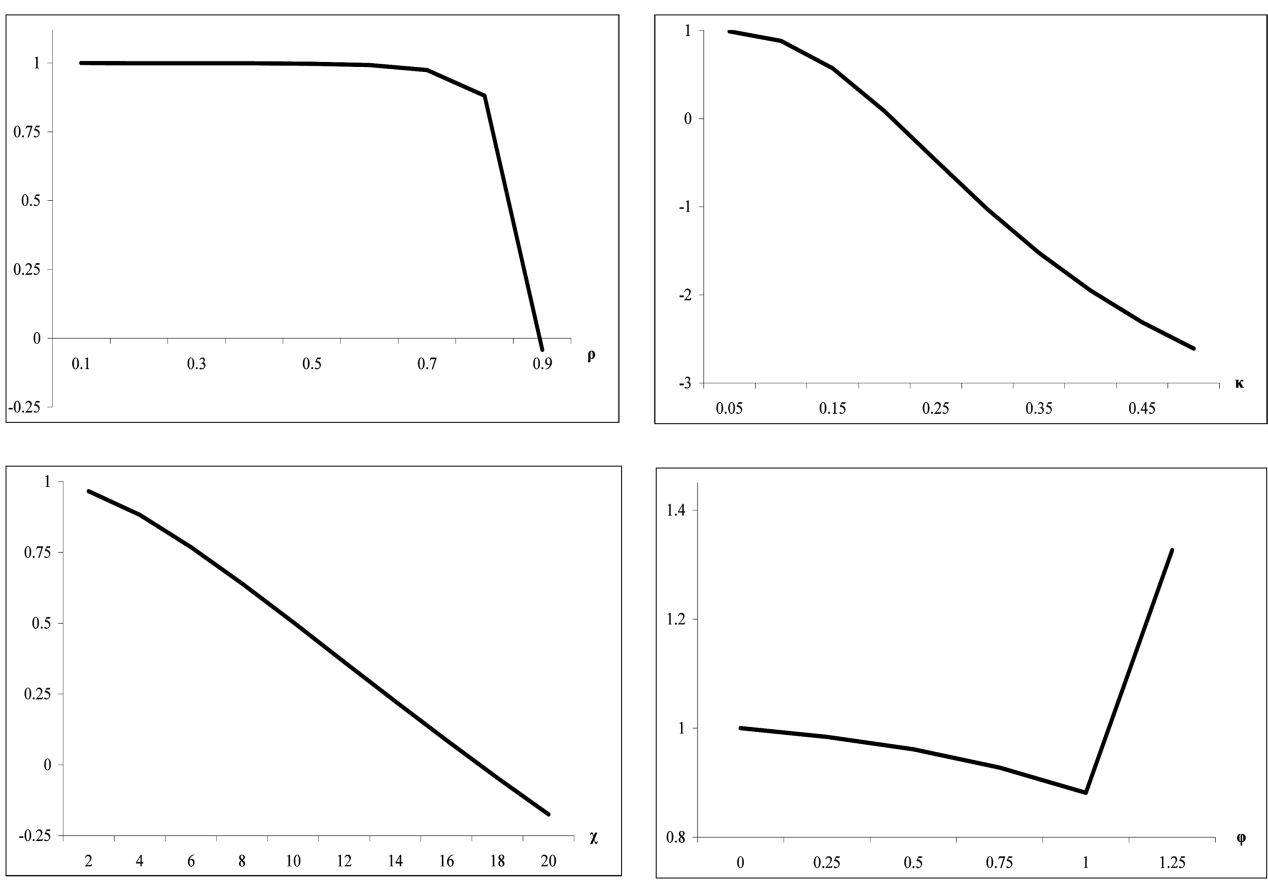

to 0.99 quarterly). For the cost-push shock autocorrelation, $\rho$, we use $\rho_{b}=0.8$ as a baseline and a range over [0.1,0.9]. The baseline value - which is above 0.3 in Jensen (2002) and 0.5 in Dennis et al. (2009) - is chosen to allow for more responsiveness in the sensitivity analysis. For the Phillips curve slope, $\kappa$, we use 0.1 as a baseline and a range over [0.05,0.5]. This baseline value is in line with Jensen (2002), with 0.2 instead being the (annualised) figure used by Tillmann (2009) and Walsh (2003b) (and estimated by Gali and Gertler, 1999). Our range allows for the higher calibrated values in Gaspar et al. (2006a, 2006b). For the weight put on price stability, $\chi$, we use a standard value of 4 as a baseline and a range over $[2,20]$. The degree of commitment/robustness, $\varphi$, is given a baseline commitment value of 1 and is allowed to vary over the range [0,1.25], which includes cases of discretion $(\varphi=0)$, incomplete commitment $(\varphi \in(0.1))$ and robustness $(\varphi=1.25) .{ }^{14}$

Figure 1 shows the threshold value of the cross-country correlation coefficient

\footnotetext{
${ }^{14}$ The choice of $\varphi=1.25$ as the highest value for this coefficient is determined by aiming to keep $1-\varphi \beta \rho$ in positive territory, given baseline calibrations of $\rho=0.8$ and $\beta=0.96$.
} 
for which the monetary package breaks even. The baseline value is 0.88 . The value of $\gamma_{i}^{*}$ varies with those of $\rho, \kappa, \chi$ and $\varphi$. For high autocorrelation of cost-push shocks (high $\rho$ ), there is a reduction in the threshold cross-country correlation, which even posts a negative value for $\rho=0.9$. This effect points to a higher welfare gain from the elimination of the stabilisation bias, whose size depends directly on the degree of shock persistence. The reduction in $\gamma_{i}^{*}$ is much less detectable for values of $\rho<0.7$. As the Phillips curve slope is larger (higher $\kappa$ ), there is a gradual decrease in $\gamma_{i}^{*}$, which turns negative for $\kappa>0.2$ and below the lowest admissible value of -1 for $\kappa>0.25$. For greater price stability concerns (larger $\chi$ ), we see a fall in the threshold cross-country correlation, which becomes negative value for $\chi>16$. Finally, as the degree of commitment is higher (higher $\varphi$ ), there is a moderate reduction in $\gamma_{i}^{*}$ to reach the baseline value of 0.88 . for $\varphi=1$. For a "robust" policy of $\varphi=1.25$, the threshold cross-country correlation turns out to exceed the feasible value of 1 .

In Figure 2, we take a different look at the magnitude of stabilisation costs relative to credibility considerations. Instead of computing the threshold value for cross-country correlation, we calibrate the latter just like the other coefficients. We calculate a welfare metric for switching from monetary autonomy to a currency union, as given by the net loss (or gain) arising from equivalent permanent inflation and output costs (i.e. $\tilde{\pi}$ and $\tilde{x}$ ). ${ }^{15}$ We conduct a sensitivity analysis by looking at how such net loss (or gain) varies with the same four parameters previously considered, but now also $\gamma_{i}$ and the standard deviation of the shock, $\sigma_{\varepsilon}$. The corresponding baseline values and ranges are 0.5 and [0.1-0.9] for $\gamma_{i}$, and 0.015 and [0.005-0.05] for $\sigma_{\varepsilon}$. The baseline value for $\sigma_{\varepsilon}$ is taken from Jensen (2002).

In Figure 2 we observe that larger values of the Phillips curve slope and the inflation policy weight (i.e. higher $\kappa$ and $\chi$ ) correspond to lower equivalent permanent inflation and output costs. These even turn negative (that is, they become gains) for $\kappa>0.15$ and $\chi>10$. The same effect can be observed (in a linear fashion) for lower values of $\sigma_{\varepsilon}$. The values of $\tilde{\pi}$ and $\tilde{x}$ react less to the remaining structural parameters. Still, lower equivalent permanent inflation and output costs

\footnotetext{
${ }^{15}$ Given that we assume output is the policy instrument, the equivalent permanent output cost can be seen in relation to the concept of "monetary stress" advanced by Sturm and Wollmershaeuser (2008), which consists of the interest rate gap between optimal policies under monetary autonomy versus the currency union. We find that, depending on structural characteristics, the "monetary policy instrument" gap may turn out to be negative, pointing to "monetary comfort" instead of "monetary stress".
} 
Figiure 2. Equivalent permanent inflation and output cost.
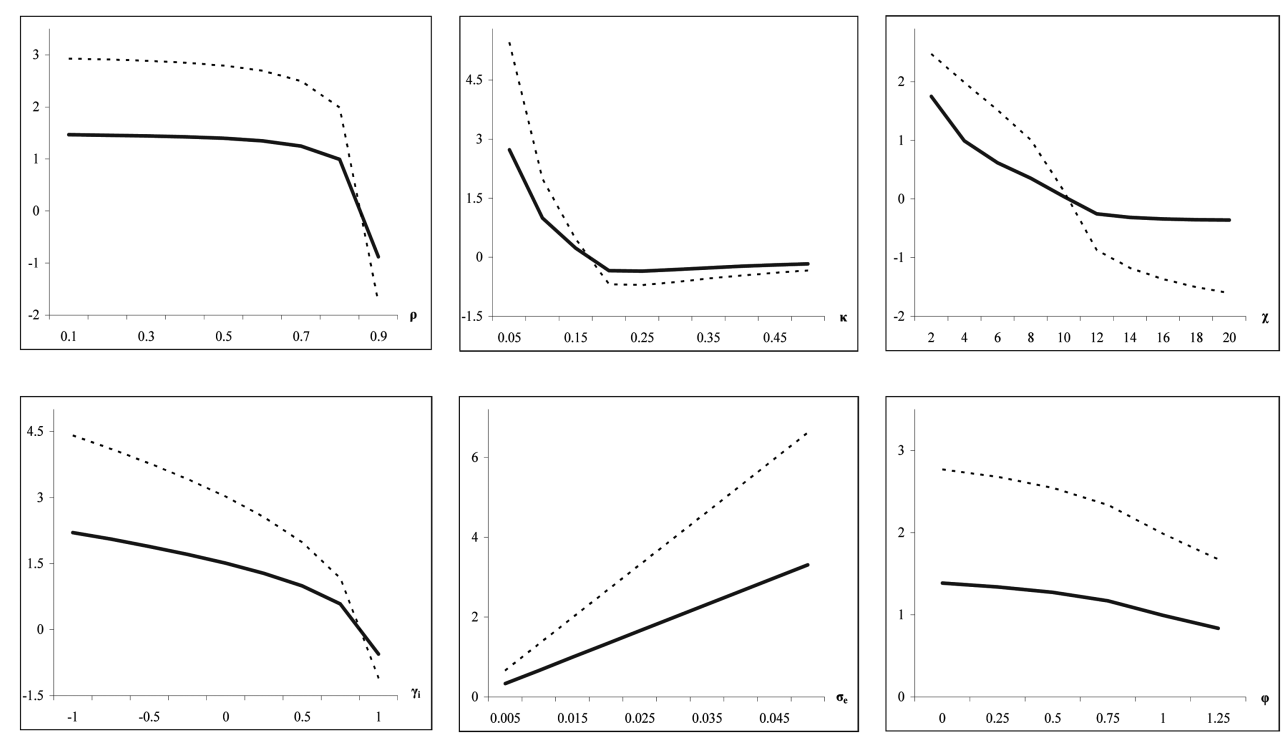

- inflation cost ------ output cost

are observed for higher values of the degree of commitment/robustness, $\varphi$, the cross-country correlation, $\gamma_{i}$, and the autocorrelation of cost-push shocks, $\rho$ - the latter again eliciting more responsive welfare effects at relatively high values.

In sum, results found using our two regime comparisons tend to be consistent with each other. Regime comparisons are quite responsive to $\chi$ and $\kappa$. For sufficient intensity in price stability concerns and nominal flexibility (directly related to the Phillips curve slope), the monetary package may thus pay off even if the reference country's cross-country correlation with the rest of the union is not too large. Lower cost-push shock variability also favours currency union membership relative to monetary autonomy. Regime comparisons react in favour of monetary union (but quantitatively much less) to a rise in the other parameters, namely, the degree of commitment, the cross-country shock correlation and the autocorrelation of cost-push shocks. The latter coefficient yields more responsive regime comparisons at rather high values, for which the stabilisation bias of the national central bank appears to play a larger role. Finally, monetary policy robustness elicits lower equivalent permanent inflation and output costs but raises the threshold cross-country shock correlation, i.e. it makes it harder for the "monetary package" to break even. 


\section{Conclusions}

The standard approach to understanding currency unions assesses the asymmetries underlying stabilisation costs, while considering credibility considerations as purely exogenous. Here we aim to extend this by comparing a currency union's stabilisation costs with credibility effects. The comparison between national monetary policy discretion with commitment in a currency union shows that joining the latter monetary arrangement gives rise to a welfare tradeoff. On the one hand, stabilisation costs arise from shocks hitting potential member states asymmetrically. On the other, discretion is known to yield an inefficient inflation stabilisation. In line with this, we find that countries pursuing discretionary monetary policies benefit from a committed common central bank, which eliminates the so-called stabilisation bias. In our model, delegation to a "conservative" central banker enables the monetary union to reach the commitment outcome. Our analysis also allows the delegation process to be "robust", by addressing shock persistence uncertainty.

We conduct two types of regime comparisons: i) in terms of the threshold value of the cross-country correlation coefficient needed for the "monetary package" involved in the currency union to break even; and ii) in terms of the equivalent permanent inflation and output cost (or gain) from relinquishing monetary sovereignty. Focusing on the latter comparison (welfare evaluation), the case for currency union membership is favoured by larger degrees of price stability concern and commitment of the common central bank, nominal flexibility (as captured by a steeper Phillips curve), and business cycle synchronisation. Monetary union stabilisation performance also improves with lower variability and higher persistence of cost-push shocks - although the latter feature is only seen for relatively high persistence. Monetary policy robustness lowers the overall costs from joining a currency union, but requires too high cross-country shock correlation for the overall monetary effects to be favourable.

The approach used here focuses exclusively on the monetary dimensions of regime comparison. This implies that currency union membership may be a desirable option even in those scenarios where the monetary effects here considered on balance would suggest against joining. This is so because of the procurrency-union role known to be played by non-monetary features such as heightened trade and financial integration. 


\section{Acknowledgements}

We gratefully acknowledge comments received at a presentation at the European Central Bank. Views expressed do not necessarily reflect those of the European Central Bank. The usual disclaimer applies.

Received 4 May 2010, Revised 4 January 2011, Accepted 24 January 2011

\section{References}

van Aarle, B., Garretsen, H., Moons, C. (2008), Accession to the euro-area: A stylized analysis using a NK model, International Economics and Economic Policy, 5, 5-24.

Angelini, P., Del-Giovane, P., Siviero, S., Terlizzese, D. (2008), Monetary policy rules for the euro area: What role for national information?, International Journal of Central Banking, 4, 1-28.

Benigno, P. (2004), Optimal monetary policy in a currency area, Journal of International Economics, 63, 293-320.

Calmfors L. (2001), Unemployment, labor market reform, and monetary union, Journal of Labor Economics, 19, 265-289.

Clarida, R., Galí, J., Gertler, M. (1999), The science of monetary policy: A NewKeynesian perspective, Journal of Economic Literature, 37, 1661-1707.

Dennis, R., Leitemo, K., Söderström, U. (2009), Methods for robust control, Journal of Economic Dynamics and Control, 33, 1604-1616.

Dennis, R., Söderström, U. (2006), How important is precommitment for monetary policy?, Journal of Money, Credit, and Banking, 38, 847-872.

Gali, J., Gertler, M. (1999), Inflation dynamics: A structural econometric investigation, Journal of Monetary Economics, 44, 195-222.

Gaspar, V., Smets, F., Vestin, D. (2006a), Adaptive learning, persistence, and optimal monetary policy, Journal of the European Economic Association, 4, 376-385.

Gaspar, V., Smets, F., Vestin, D. (2006b), Monetary policy over time, Macroeconomic Dynamics, 10, 207-229.

Giannoni, M. (2007), Robust optimal monetary policy in a forward-looking model with parameter and shock uncertainty, Journal of Applied Econometrics, 22, 179-213.

Hansen, L., Sargent, T. (2008), Robustness. Princeton University Press, Princeton.

Jensen, H. (2002), Targeting nominal income growth or inflation?, American Economic Review, 92, 928-956.

Lombardo, G. (2006), Inflation targeting rules and welfare in an asymmetric currency area, Journal of International Economics, 68, 424-442.

Rogoff, K. (1995), The optimal degree of commitment to an intermediate monetary target, Quarterly Journal of Economics, 100, 1169-1189. 
Sánchez, M. (2010), Wage restraint and monetary union, Economic Modelling, 27, 134-142. Sturm, J.-E., Wollmershaeuser, T. (2008), The stress of having a single monetary policy in

Europe, Cesifo Working Paper No. 2251.

Svensson, L. (1997), Optimal inflation targets, conservative central banks, and linear inflation contracts, American Economic Review, 87, 98-114.

Tillmann, P. (2009), The stabilization bias and robust monetary policy delegation, Journal of Macroeconomics, 31, 730-734.

Walsh, C.E. (2003a), Monetary Theory and Policy, MIT Press, Cambridge.

Walsh, C.E. (2003b), Speed limit policies: The output gap and optimal monetary policy, American Economic Review, 93, 265-278.

\section{Appendix}

\section{A. Commitment and "conservative" central banking in a monetary union}

Here we show that, in a currency union, the commitment outcome can be achieved by appointing a "conservative" SMA (denoted by $u c$ ), with an inflation weight $\chi^{u c}=\chi^{P} /(1-\beta \rho)$, where $\chi^{P}$ is the social planner's corresponding weight. ${ }^{16}$ To see this, notice that the social planner sets $\chi^{u c}$ to minimise

$$
\sigma_{\varepsilon}^{2}\left\{\left[\frac{\kappa \chi^{u c}}{1-\beta \rho+\kappa^{2} \chi^{u c}}\right]^{2}+\chi^{P}\left[\frac{1}{1-\beta \rho+\kappa^{2} \chi^{u c}}\right]^{2}\right\}
$$

The optimal weight is found to be $\chi^{u c}=\chi^{P} /(1-\beta \rho)$. Given that $\beta \rho<1$, the optimal inflation weight lies above the social planner's corresponding weight (in the spirit of Rogoff, 1985).

Applying the same logic leading to (4) under monetary autonomy, equilibrium inflation for a discretionary currency union (labelled $u d$ ) can be expressed as

$$
\pi_{t}^{u d}=\frac{1}{1-\beta \rho+\kappa^{2} \chi^{P}} \varepsilon_{t}
$$

which using the optimal value for $\chi^{u c}$ can be expressed as

$$
\pi_{t}^{u c}=\frac{1-\beta \rho}{(1-\beta \rho)^{2}+\kappa^{2} \chi^{u c}} \varepsilon_{t}
$$

which reproduces the commitment outcome in (8).

\footnotetext{
${ }^{16} \chi^{p}$ is assumed to be known and fixed, albeit not necessarily equal to $\chi^{u e}$ nor the "robust delegation" weight, $\chi^{u r}$, which was introduced in subsection II. B.
} 